\title{
The experiences of second generation Samoans in Australia
}

\author{
Glenda Stanley \\ Griffith University \\ Judith Kearney \\ Griffith University
}

\begin{abstract}
Australia is a culturally diverse country with increasing numbers of people with Samoan heritage immigrating in search of better educational and employment opportunities. Indicators such as under-representation in university courses and employment outcomes point to adaptation difficulties for many second generation Australians with Samoan heritage, setting them apart from some other immigrant groups in Australia. This paper aims to provide a better understanding of the experiences of this Samoan cohort of young people and to suggest ways or pathways to better opportunities and outcomes. This is achieved through content analysis of eleven in-depth interviews. The findings reveal two key themes: protective factors for strong cultural identity and social connectedness; and constraints on educational opportunities. Findings also showed that some interactions with churches, friends and parents constrain educational opportunities. The paper concludes by reflecting on a suggestion that parents of Samoan young people reconsider traditional practices that might limit communicative interactions with their children. It also recommends a collaborative response from parents, families and church groups to help resolve competing demands on young people of Samoan heritage in Australia.
\end{abstract}

Keywords: Samoan, second generation, social inclusion

The introduction of the Trans Tasman Travel Arrangement (TTTA) in 1973 has allowed free movement of people between New Zealand and Australia, with the opportunity for citizens of both countries to live and work indefinitely in each other's countries (Hamer, 2014; Kearney \& Glen, 2017). The TTTA has encouraged a strong pattern of migration to Australia from Pacific nations via New Zealand. By December 2015, there were approximately 634,560 New Zealand citizens residing in Australia (Spinks \& Klapdor, 2016), many with Samoan heritage who have relocated in search of education and employment opportunities (Fa'avale, O'Brien, Green, \& McLaughlin, 2016; Horton, 2014).

Within this group are second generation Australians, who were born in Australia or New Zealand, but whose parent or parents were born in Samoa. Unfortunately, many second generation Australians of Samoan descent have not experienced the education and employment opportunities that prompted their parents' migration to Australia (Cuthill \& Scull, 2011; Kearney \& Glen, 2017). Instead, those with New Zealand citizenship, whose parents are unable to meet the qualifying criteria for permanent residence in Australia, have been marginalised and excluded by a series of legislative shifts since 2001 (Hamer, 2014; Kearney \& Glen, 2017), affecting their access to certain social security payments and eligibility for the Higher Education Contribution Scheme (HECS) - a loan scheme available for Australian students to complete university studies.

Corresponding author: Glenda Stanley (g.stanley@griffith.edu.au) 
Challenges for this second generation may include identity tensions. Typically, a Samoan identity is a relational identity based on collectivist ideals (Tamasese, Peteru, Waldegrave, \& Bush, 2005; Tiatia, 2012) where individuals have a strong sense of responsibility to their social groups. In contrast, the dominant Australian identity is underpinned by the ideal of individualism (Noordin \& Jusoff, 2010). Samoan communities usually endorse a traditional, vertically structured social orientation where hierarchy is a given, and the roles and status assigned to community members are clearly defined (Stewart-Withers \& O'Brien, 2006; Tunufa'i, 2013). However, in Australia the dominant social orientation of the Anglo-Australian community favours a more horizontal, egalitarian orientation (Hofstede, 1980, 2001). Therefore, the second generation, may contend with two competing sets of cultural orientations. The inability to resolve competing demands may cause acculturative stress and prevent development of a well-defined identity (Berry, 2005).

Whereas all identity formation may be seen as "complex, situational, and dynamic" (Bauer, Loomis, \& Akkari, 2013, p67), second generation Australians with Samoan heritage share some distinctive characteristics shaped by their life circumstances. The research literature suggests this common aspect of their identity is tempered by tensions afforded by moving in two non-aligned worlds associated with home and school (Benham, 2006; Kearney, Fletcher, \& Dobrenov-Major, 2011). While research in an Australian context remains limited, studies in New Zealand have shown that the second generation have been caught between cultures; and pulled between obligations to their Island heritage and participation in Western society (Anae, Anderson, Benseman, \& Coxon, 2002; Manuela \& Sibley, 2015; Tiatia, 2012).

Tiatia $(1998,2012)$ explained that Samoan elders may regard their young peoples' westernised thinking as a threat to cultural traditions, while schools may disregard and discount Samoan students' cultural knowledge. We propose that in Australia many Samoans who are second generation Australians may journey on a similar conflicting path. Ironically, their parents' emigration from Samoa, often via New Zealand, is likely to have been prompted by perceived opportunities for a better life for their children resulting in economic gain and social mobility (Benseman, Coxon, Anderson, \& Anae 2006; Cuthill \& Scull, 2011; Hamer, 2014; Vaughan, Schubert, Mavoa \& Fa'avale, 2017). However, indicators associated with participation levels in higher education and employment suggest many of their children have not gone on to realise these opportunities (Kearney \& Glen; 2017).

There is a tendency for Samoan families to settle in areas with an extensive co-ethnic community (Ravulo, 2015). This strong Samoan presence within a local community affirms the immigrant family's cultural beliefs and values. As Christianity is central to the lives of most Samoan families (Levine, 2003; Tiaitia, 1988, 2012), providing a focus for community activities (Vasta, 2004), the church plays a significant role in supporting family stability and cultural values. For many Samoan immigrants, church congregations in Australia assume the role of village societies in Samoa, with church ministers inheriting the power and influence of village matais or chiefs (Levine, 2003). This means that churches in resettlement areas fulfil both spiritual and cultural needs of members, acting as "custodians of Pacific culture and nuance" (Periera, 2004, p29). Churches help to maintain the fa'a Samoa, a phenomenon which encompasses the cultural beliefs and values including love, respect, family and reciprocity which embody the essence of being Samoan (Levine, 2013; Thornton, Binns, \& Kerslake, 2013).

It is important to understand the needs of second generation Samoans to support opportunities that enable their full participation within the Australian context. This is significant as their adaptation determines, or is at least instrumental in, the future of successive generations and the long-term effects of immigration for families (Portes, Fernandez-Kelly, \& Haller, 2009). In this study, we aimed to listen to the experiences of younger, second generation Samoans residing in Australia to deepen our understanding of ways to provide support that lead to opportunities in line with their personal aspirations. The question guiding 
the study is: What are the experiences of Samoan-heritage, second generation, Australian youth, and how do these experiences shape their sense of belonging and/or ability to participate in Australian society?

\section{Method}

An interpretivist paradigm using qualitative research methods was adopted in this study. This involved the use of interview data that drew on the lived experiences of 11 people (eight females, three males), aged 16 to 27 years. All participants had Samoan heritage and were second generation Australians. Ten of the group were born in New Zealand and came to live in Australia as children while one was born in Australia. Two participants were married or living with a partner and young children. One was divorced with three children. Most were single and continued to live in the family home. Participants included two secondary students, one tertiary student, a community worker, two factory workers, three office workers and two with home duties. English was the first language for all, while five acknowledged fluent bilingualism, six reported that they had only limited ability in Samoan. In most cases, participants were members of small Christian church communities catering for Samoan families. Ethics approval was obtained for the study.

A female member of the Samoan community conducted the interviews. She was known to all participants whom she had identified from a wide network of friends or friends-of-friends therefore purposefully selecting second generation participants. This was a deliberate strategy to encourage a context of trust and openness for the interviews. The interviewer explained the purpose of the project to each potential participant. Having obtained their voluntary participation, she arranged for a time and venue nominated by each participant. In most cases, interviews were conducted in their homes and audiotaped with the participants' written and verbal consent.

Interviews were transcribed with names altered to protect the anonymity of participants. Data were then analysed using Leximancer, which is a content analysis tool used to analyse interview data and to provide five sources of information about the data: (a) the main concepts discussed in the data set; (b) the relative frequency of each concept; (c) the co-occurrence of concepts; (d) the centrality of concepts; and (e) thematic groups which define co-occurring concepts (Smith, 2007; Smith, 2011). As a tool for content analysis of text, Leximancer mitigates subjectivity associated with human analysis and is a quick process to identify key concepts in participants' narratives when an extensive data set requires analysis (Smith \& Humphreys, 2006).

We obtained a list of meaningful concepts ranked by frequency. Two key concepts, or terms, that co-occurred most frequently for participants were 'church' and 'friends'. These concepts were explored using a mechanism provided by Leximancer that locates qualitative comments illustrating issues associated with the concepts. We then manually coded these comments for themes.

\section{Findings}

Emergent themes clustered as two categories for each key concept: a) protective factors for a strong cultural identity and social connectedness; and b) constraints on opportunities. Sub themes relating to both were identified with recurring emphasis placed on the influence of church and friendship groups on belonging and participation. Parents were also discussed in detail when referring to the above sub-themes, and will be considered within the sub-themes of church and friendships. 


\section{Church - Protective factor for a strong cultural identity and social connectedness}

A strong sense of pride in being Samoan was expressed, with churches nominated as significant sites for cultural reproduction. All participants had a strong connection with a church and spoke extensively about their experiences. Attendance at church was expected and enforced by parents, and there were clear expectations about children's behaviour at church. Lia, a 23-year-old university student, explained that in church children were expected to pay attention and listen: 'Once you're in church you are always told no kids are allowed to talk or scream or cry or whatever. A kid has to pay attention and sort of act like an adult; like act older'.

The function of churches extended beyond their congregation's spiritual well-being to include explicit teaching of traditional cultural expectations and behavioural norms consistent with the fa'a Samoa. Through church events, the Samoan community promoted retention of the immigrant culture and encouraged family contexts where children learned respect and obedience for parents and elders. Attendance at church allowed participants to learn and understand cultural practices, and to appreciate roles and relationships within the Samoan culture. It helped them to define their 'Samoan-ness' and promoted a Samoan identity that maintained an appreciation of cultural traditions. "It has influenced me hugely in how I am a Samoan now', explained Joy, a 21-year-old office worker, who had attended a Samoan church for most of her life, 'just the fa'a Samoa in our own church and the whole respect for elders that came through church'.

Church attendance was also found to help develop and maintain Samoan language. As Willie, a 17-year-old high-school student, commented: 'Being around Samoans helps you a lot to speak Samoan and being in a Samoan church will definitely help you along with your fa'a Samoa and learning to speak'. Churches encouraged bilingualism within the second generation through reciting of biblical passages and prayers in Samoan.

\section{Church - Constraints on opportunities}

Our data showed that nine of the eleven young people believe that their commitment to church activities reduced time for school assignments and affected their school attendance. For example, Neta, a 17-year-old mother performing home duties, emphasised the importance and priority of church for Samoan families: 'Parents expect their kids to drop everything and do church first'. Neta further explained by giving an example: 'One time I asked my friend if she could come out to do an assignment together, and she said no because her mum would rather her be somewhere doing something for church'. Mark, a 26-year-old factory worker, agreed with Neta about the importance of church for parents: 'A lot of church things took up our time where parents tend to forget that we have school. If we had something going on at church and we needed to have practices, we practised till late and we were late the next morning at school. Our mind wasn't there; it was at the weekend'. Lia also described church activities as time consuming, explaining that, 'You had to do everything for church and then you got to go to school. You always got to school late or didn't finish an assignment'. Kali, a 16-year-old high-school student, found it difficult to meet church commitments and those associated with her schooling, commenting: 'There is always something going on with church so I have to help out with that and it's the whole weekend'; and 'Saturday is a big church meeting and then Sunday is church and you never get a thing done on Sunday'. Kali believed that her parents did not understand how church negatively affected her schooling. She saw no way to change the situation, stating, 'That's just the way it is'.

Our participants' comments illustrated some frustration as church activities competed with their school commitments and possibly limited their opportunities for educational achievement. They doubted they could successfully accommodate both sets of obligations, recognising the inherent tension between the two. Commitment to church maintained Samoan youth's collective or traditional identity, while commitment to education challenged and confronted that identity. Peka, a 26-year-old community worker, explained, 'Education is going out on a limb 
to try to create something different for yourself. It's really saying to the others that I'm better than you'. According to Peka, pursing higher education was problematic, as her desire to become educated was interpreted by others around her as trying to be fia poto or fia maualaga, trying to be smarter and/or higher (Gershon, 2007; Hardin, 2016). She shared the challenges of having to distance herself from her community to fulfil her goal of obtaining a university degree, which may have been interpreted as a rejection of the collective values and practices by those close to her.

Evidence of financial constraints were also identified. Participants were especially critical of some churches' encouragement of fa'alavelave, a cultural practice involving the reciprocal giving of gifts and money at events, including weddings, funerals, the bestowing of titles, or church dedications. In island villages, Samoan matai or chiefs had responsibility for the practice of fa'alavelave, but churches maintained the practice in diasporic communities (Levine 2003). Participants spoke about cultural obligations related to giving, especially to the church. Rona, a 23-year-old office worker, insisted that expectations to give remained, even when financial resources were limited. 'Because of the fa'a Samoa you have to give', she claimed, 'being a Samoan you have to give, give, give, give and it's not so much about receiving. You always have to give and sometimes you don't have anything to give and so you go out and you get into debt and stuff just so you can give'.

Sina, a 24-year-old mother involved in home duties, explained that, while the fundamental values of the church were important to her, she often felt overwhelmed by religious customs and ceremonial traditions. She believed that the emphasis on giving had resulted in unhealthy competition amongst families, commenting that, 'It starts to be about image and who can give the most. You know, which family can give the most'; 'it's pretty sad because my family probably gave the most and ended up with nothing anyway. Religion and cultural stuff don't mix'. While church was viewed as important to participants, the financial demands of supporting and maintaining some religious and cultural practices was regarded as detrimental for them and their families (Cowley, Paterson, \& Williams, 2004).

\section{Friends - protective factor for creating sense of belonging and connection}

All participants valued the support provided by Samoan friends. 'Samoan kids will do anything for their friends', said Faye, a 22-year-old office worker. Participants commented that it was easy to form friendships with other Samoans and these friendships reinforced a collective Samoan identity along with an interest in maintaining that cultural identity. 'If I went to a new school I would automatically have a connection with other Samoans', Joy explained, 'Even when I go to work, if I see a new face and they are Samoan I would have an instant connection with that person whereas it would be harder for me to create a friendship with a non-Samoan person'.

Iva, a 23-year-old factory worker, offered an explanation for the ease of making friends with other Samoans: 'When you are a minority then you bond with the people who are like you. It's really easy to join with people who are like-minded when you are not the majority'. Faye found that her Samoan friends kept her grounded in the culture: 'They keep reminding me of the boundaries, like if we go to other families we are expected to go into the kitchen and stuff to help', thus reinforcing cultural roles and expected behaviours for young women (and men) within community settings.

Neta also valued her Samoan friends and their friendship. She explained, 'They [friends] can relate to you and home life and schooling life and other experiences'. Sina reported that she and her Samoan friends shared common experiences and supported each other as they tried to reconcile the conflicting worlds of home and school. This was particularly important when supporting each other through parents' disciplining practices. Sina explained, 'It was just a way of leaning on each other really, having a friend - a Samoan friend, and understand exactly what you're going through'; and 'We knew what was going on. No one else knew, you know. 
It was just no one was allowed to say anything, but we all knew. There were always spoken words in the silence'. The unspoken acknowledgement and understanding of shared experiences between Samoan friends supported participants as they navigated their nonaligned worlds of school, home and church.

Joy suggested that opportunities to communicate with her Samoan friends had helped her to develop effective interpersonal skills, which she saw as important for Samoan immigrant youth. 'If you had more traditional Samoan parents it would probably be a lot harder to, you know, make friends', Joy said, 'Not because nobody likes you but because you find it hard to approach someone because of the way you have been brought up not to speak'. Joy did not see similar issues for future generations: 'For the younger generation that are now parents, I think it's a lot easier for them because they have been brought up in New Zealand or Australia in a Palagi [European] world where they are basically used to the Palagi lifestyle', and thus would be more able to communicate openly and more confidently with parents and peers.

\section{Friendship - Constraints of belonging to the collective}

While their friendships with other Samoans were enabling in many ways, there were times when attitudes and behaviours that came from some Samoan friendships were expressed by participants as restraining educational opportunities. 'You get some Samoan friends that pull you down when they're down as well shared Neta. 'There are so many Samoans with the dream of what they want to be in life', said Willie, 'but there are so many friends that want to pull them down from that'. Kylie, a 16-year-old high school student admitted that her Samoan friends could provide distraction. She explained that her friends were living up - or perhaps down - to others' expectations of limited achievement: 'I think they just try to live up to the name they're given - like as underachievers'. Kylie was conscious that the behaviours and attitudes of her Samoan friendship group reinforced negative stereotypes and labels at school. Having different classes from her peers enabled her to focus on her schooling, without being distracted by her peers 'living up' to stereotypes and labels.

Several participants spoke of communication difficulties within families where parents endorsed traditional cultural beliefs about the status and social roles of parents and their children. These beliefs influenced the type of interactions young people experienced with their parents, which included parents instructing children, and children obeying their parents. Willie explained, 'Most Samoan boys don't talk that much. They keep it to themselves. In the home, the children hardly ever talk about things to their parents that they would want to'. Willie was cautious as he shared, very conscious of his words and not wanting to dishonour or 'hurt' his parents with his views; views he felt unable to share with them.

Non-Samoan friends served a different purpose from Samoan friends. Whereas Samoan friends provided empathy with each other and encouraged conformity across the group, nonSamoan friends afforded opportunities outside the Samoan community. 'They made me open up to everything that's not so much exposed in the Samoan community,' said Faye. In particular, observations of non-Samoan friends' interactions with their parents made participants question traditional beliefs that influenced communicative practices between parents and their children in Samoan immigrant families. 'I had a lot of Australian friends and I envied them. I really did. I really wished that I was them at times', said Sina, 'It was the freedom that they had to be able to talk to their parents'. The opportunity to dialogue 'openly' with parents was important along with the space to express ideas, and to respectfully agree and/ or disagree without negative repercussion.

\section{Discussion}

The experiences shared by second generation Australians with Samoan heritage, provide insight into the protective and constraining factors influencing their sense of belonging and 
ability to participate in Australian society. This study reinforces concerns about identity tensions for this second generation of young Australians who contend with two competing sets of cultural orientations. Unfortunately, the same issues identified by Tiatia (1998) in a New Zealand context almost two decades ago persist in a contemporary Australian context. And ironically, the influence of key social institutions such as church communities and friendship groups, while supporting the wellbeing of young people, foster identity tensions.

Tiatia (1998), Anae (2003), and Thornton, Kerslake, and Binns (2010), described Samoan youth's dual obligations to their island heritage and to their participation in Western society. While these studies were conducted in New Zealand, the same tension exists for the study participants in Australia. The desire to maintain one's Samoan cultural values and practices while also embracing the opportunities afforded in Australian society were often conflicting.

Churches support families in transmitting cultural knowledge to their children, and encourage maintenance of the Samoan language. However, for the participants in this study, their churches' positive influence competes with a set of circumstances that places constraints on opportunities. According to participants, their church communities enable Samoan cultural traditions to dominate congregational practices, with traditions referred to as fa'alavelave placing financial strain on families. This may explain, in part, the decrease of membership within traditional Samoan churches and increased participation in more contemporary churches (Thornton, Kerslake, \& Binns, 2013; Tunufa'i, 2005). In addition, families' commitments to their churches are often prioritised over educational activities. This may restrict young people's opportunities to gain the educational credentials that are necessary for social mobility and a wide choice of career options (Kearney \& Glen, 2017).

Similarly, the role of Samoan friendships may assist identity formation on the one hand, and perpetuate identity tensions on the other. Friendships with other Samoans assist in two ways. First, Samoan friendships help to reinforce a collective Samoan identity and stimulate interest in maintaining that cultural identity. Second, Samoan friends provide understanding and support when individuals struggle with their circumstances. However, Samoan friends who live up to expectations of perpetuating limited educational achievement can encourage attitudes and behaviours that restrain educational opportunities for themselves and their peers.

Change is needed to better support the second generation's sense of belonging and ability to fully participate in Australian society, and in particular, in relation to facilitating educational achievement. Samoan parents have a significant role to play in the change process. A willingness is required by parents to re-think aspects of traditional practices that limit communicative interactions with their children, without compromising the issue of their parental authority or lessening their children's respect. This will presumably provide further insights and benefits. It is clear that second generation young people confront a unique set of challenges in managing their parents' encouragement of traditional Samoan practices while meeting expectations of participation in their Australian homeland. Dealing with these tensions requires support, guidance and particularly understanding from their parents, not just from their friends. This suggests the need for more agentic communication between parents and children where children are respectfully able to express themselves without this being perceived as challenging or threatening parents' authority.

In addressing these changes, Samoan parents and young people also need support from their church and school communities. Churches with significant numbers of Samoan immigrant families must advocate for and/or undertake a mediating role in the process as they hold the confidence of these families (Agnew et al., 2004; Anae et al., 2002). Similarly, opportunities to engage with school and to work collaboratively with churches should also assist in gaining the confidence of their immigrant parents, and encourage and support them as active 
participants or partners in their children's educational journey (Fletcher, Parkhill, Fa'afoi, \& O’Regan, 2009; Kearney, 2012; Siope, 2011).

\section{Limitations}

Having a member of the Samoan community conduct the interviews afforded access and encouraged rapport between the interviewer and the participants. However, an 'insider approach' also has its limitations. For example, participants were limited to the interviewers' network of friends who resided in neighbouring suburbs. Thus, the study sample was small and limited by location and breadth of participants and cannot be assumed as being representative of the broader group of Samoan-descent second generation Australians. Being known to participants will have facilitated cultural safety, however, may also have presented some challenges regarding the openness of participants. Nevertheless, although findings cannot be generalised to the broader population, they do provide valuable insights to inform more effective ways to engage and support this particular group of second generation Australians. As limited literature is available on this cohort, further research is required to determine the broader applicability of findings, and to identify ways to improve support strategies and outcomes.

\section{Conclusion}

Protective factors for second generation Australians with Samoan heritage that promote strong cultural identity and social connectedness include church, friendship groups and parents. However, as shared by participants in this study, they can also be constraining. The Samoan immigrant community in Australia is growing rapidly, with significant numbers in the younger age groups. Current educational performance and participation demographics for Samoan immigrants in Australia suggest little room for complacency. Indeed, they indicate an urgent need for a collaborative response from families, church groups, and schools to better support young people of Samoan heritage. This partnership and cooperation is essential so that Samoan young people, now and in the future, can fully embrace the opportunities for economic gain and social mobility that motivated their forebears' original immigration to Australia. 


\section{References}

Agnew, F., Pulotu-Endemann, F. K., Robinson, G., Suaalii-Sauni, T., Warren, H., \& Wheeler, A. (2004). 'Pacific models of mental health service delivery in New Zealand (PMMHSD) Project', Health Research Council of New Zealand, Mental Health Commission. Auckland: Ministry of Health.

Anae, M. (2003). 'O a'u/l: my identity journey', Fairbairn-Dunlop, P. \& Sisifo Makisi, G. (Eds), Making our place: growing up PI in New Zealand. Palmerston North: Dunmore. pp. 89101.

Anae, M., Anderson, H., Benseman, J., \& Coxon, E. (2002). 'Pacific peoples and tertiary education: Issues of participation'. Final Report. Auckland, New Zealand, University of Auckland, 161.

Bauer, S., Loomis, C., \& Akkari, A. (2013). 'Intercultural immigrant youth identities in contexts of family, friends and school', Journal of Youth Studies, 16 (1): 54-69.

Benham, M.K.P. (2006). 'A challenge to Native Hawaiian and Pacific Islander scholars: What the research literature teaches us about our work', Race Ethnicity and Education, 9 (1): 29-50.

Benseman, J., Coxon, E., Anderson, H., \& Anae, M. (2006). 'Retaining non-traditional students: lessons learnt from Pasifika students in New Zealand', Higher Education Research \& Development, 25 (2): 147-162.

Berry, J.W. (2005). 'Acculturation: Living successfully in two cultures', International Journal of Intercultural Relations, 29: 697-712.

Cowley, E.T., Paterson, J., \& Williams, M. (2004). 'Traditional gift giving among Pacific families in New Zealand', Journal of Family and Economic Issues, 25 (3): 431-444.

Cuthill, M., \& Scull, S. (2011). 'Going to university: Pacific Island migrant perspectives', Australian Universities' Review, 53 (1): 5-13.

Fa'avale, A., O'Brien, G., Green, A., \& McLaughlin, J. M. (2016). 'May the coconut tree bear much fruit'-QUT's' niu'framework for outreach and retention with Pasifika students', paper presented at the Students Transition Achievement Retention and Success Conference, Perth, Australia.

Fletcher, J., Parkhill, F., Fa'afoi, A., \& O'Regan, B. (2009). 'Pasifika students: Teachers and parents voice their perceptions of what provides supports and barriers to Pasifika students' achievement in literacy and learning', Teaching and Teacher Education, 25 (1): 24-33.

Gershon, I. (2007). 'Compelling culture: The rhetoric of assimilation among Samoan migrants in the United States', Ethnic and racial studies, 30 (5): 787-816.

Hardin, J. (2016). 'Claiming Pule, Manifesting Mana: Ordinary Ethics and Pentecostal Self-making in Samoa', NEW MANA, 257.

Hamer, P. (2014). 'Unsophisticated and unsuited': Australian barriers to Pacific Islander immigration from New Zealand', Political Science, 66 (2): 93-118.

Hofstede, G. (1980). Culture's consequences: International differences in work-related values. Beverley Hills, CA: Sage.

Hofstede, G. (2001). Culture's consequences: Comparing values, behaviors, institutions and organizations across nations. Thousand Oaks, CA: Sage.

Horton, P. (2014). 'Pacific Islanders in professional rugby football: Bodies, minds and cultural continuities', Asia Pacific Journal of Sport and Social Science, 3 (3): 222-235.

Kearney, J. (2012). 'Unlucky in a lucky country: A commentary on policies and practices that restrict access to higher education in Australia', Journal of Social Inclusion, 3 (1): 130134.

Kearney, J., \& Glen, M. (2017). 'The effects of citizenship and ethnicity on the education pathways of Pacific youth in Australia', Education, Citizenship and Social Justice, 12 (3): 277-289. 
Kearney, J., Fletcher, M., \& Dobrenov-Major, M. (2011). 'Non-aligned worlds of home and school: A case study of second-generation Samoan children', Journal of Family Studies, 17: 146-156.

Levine, H. (2003). 'Some reflections on Samoan cultural practice and group identity in contemporary Wellington, New Zealand', Journal of Intercultural Studies, 24 (2): 175186.

Manuela, S., \& Sibley, C. G. (2015). 'The Pacific Identity and Wellbeing Scale-Revised: Comparisons across Pacific groups', John Fitzgerald, 44 (1): 60.

Noordin, F., \& Jusoff, K. (2010). 'Individualism-collectivism and job satisfaction between Malaysia and Australia', International Journal of Educational Management, 24 (2): 159-174.

Pereira, T. (2004). 'A Pacific perspective on physical punishment', Children's Issues, 8 (2): 27-29.

Portes, A., Fernández-Kelly, P., \& Haller, W. (2009). 'The adaptation of the immigrant second generation in America: A theoretical overview and recent evidence', Journal of Ethnic and Migration Studies, 35 (7): 1077-1104.

Ravulo, J. (2015). 'Pacific Communities in Australia'. Accessed 27 July 2017. http://researchdirect.westernsydney.edu.au/islandora/object/uws\%3A31311/datastre am/PDF/view

Siope, A. (2011). 'The schooling experiences of Pasifika students', SET: Research Information for Teachers, 3: 10.

Smith, A. (2007). Leximancer Manual 2.23. Leximancer Manual (Version 2.23). The University of Queensland. Accessed 10 October, 2013. https://www.leximancer.com/wiki/images/archive/7/77/20080826071142! Leximancer V2 Manual.pdf

Smith, A., \& Humphreys, M.. (2006). 'Evaluation of unsupervised semantic mapping of natural language with leximancer concept mapping', Behaviour Research Methods, 38 (2): 262-279.

Smith, J. A. (2011). 'Evaluating the contribution of interpretative phenomenological analysis: A reply to the commentaries and further development of criteria', Health psychology review, 5 (1): 55-61.

Spinks, H. \& Klapdor, M. (2016). 'New Zealanders in Australia: a quick guide', Parliament of Australia. Accessed 27 July, 2017. http://www.aph.gov.au/About_Parliament/Parliamentary_Departments/Parliamentary Library/pubs/rp/rp1617/Quick_Guides/NZAust.

Stewart-Withers, R., \& O'Brien, A. P. (2006). 'Suicide prevention and social capital: A Samoan perspective', Health Sociological Review, 15: 209-220.

Tamasese, K., Peteru, C., Waldegrave, C. \& Bush, A. (2005). 'Ole aeao Afua, the new morning: A qualitative investigation into Samoan perspectives on mental health and culturally appropriate services', Australian and New Zealand Journal of Psychiatry, 39: 300-309.

Thornton, A., Binns, T., \& Kerslake, M. T. (2013). 'Hard times in Apia? Urban landlessness and the church in Samoa', Singapore Journal of Tropical Geography, 34 (3): 357-372.

Thornton, A., Kerslake, M. T., \& Binns, T. (2010). 'Alienation and obligation: Religion and social change in Samoa', Asia Pacific Viewpoint, 51(1): 1-16.

Tiatia, J. (1998). Caught between Cultures: A New Zealand-Born Pacific Island Perspective. Auckland: Christian Research Association.

Tiatia, J. (2012). 'Commentary on 'Cultural Diversity Across the Pacific': Samoan Cultural Constructs of Emotion, New Zealand-Born Samoan Youth Suicidal Behaviours, and Culturally Competent Human Services', Journal of Pacific Rim, 6 (02): 75-79.

Tunufa'i, L. (2013). E Agatonu a Manu'a o Fesili: investigating the attitudes of an Auckland Samoan population toward the New Zealand criminal justice system (Doctoral dissertation, Auckland University of Technology).

Tunufa'i, L. F. (2005). The price of spiritual and social survival: investigating the reasons for the departure of young New Zealand-born Samoans from a South Auckland Samoan 
Seventh-day Adventist Church (Doctoral dissertation, Auckland University of Technology).

Vaughan, L., Schubert, L., Mavoa, H., \& Fa'avale, N. (2017). "Hey, We Are the Best Ones at Dealing with Our Own': Embedding a Culturally Competent Program for Māori and Pacific Island Children into a Mainstream Health Service in Queensland, Australia', Journal of Racial and Ethnic Health Disparities, 1-12.

Vasta, E. (2004). 'Community, the state and the deserving citizen: Pacific islanders in Australia', Journal of Ethnic and Migration Studies, 30 (1): 195-213. 


\section{Biographical Notes}

Tagaloa Glenda Stanley is completing a Doctorate of Education at Griffith University, researching the aspirations of Pacific Island High School Students to Higher Education, and is also employed as the Careers Outreach Coordinator for Student Diversity and Inclusion, Student Services. Glenda has worked extensively over the past 12 years facilitating complex community and government forums to enhance positive outcomes for young people and Pacific communities in Australia. She has led key initiatives both nationally and internationally, to raise awareness and support aspirations of educational opportunities for Pacific communities. A number of these initiatives have received state and national awards raising the profile and work of Pacific Peoples in Australia.

Judith Kearney is an Associate Professor in the School of Education and Professional Studies at Griffith University. Her research interests focus on literacy pedagogy and the effects of cultural and linguistic diversity on teaching practice, and social inclusion issues and community development. Judith is working with community organisations such a Voice of Samoan People (VOSP) to enhance educational opportunities for its members. This involved a federally-funded investigation of Samoan children's home-school literacy transition and three community partnership projects involving the Samoan, and other Pacific Island, communities. This work has involved the production of bilingual children's books, and the conduct of mentoring projects to raise the aspirations of Pacific Island students in secondary schools and to facilitate their transition to higher education. 